\title{
Introduction
}

\section{Georges Didi-Huberman}

\section{OpenEdition}

\section{Journals}

Édition électronique

URL : http://journals.openedition.org/imagesrevues/276

DOI : 10.4000/imagesrevues.276

ISSN : 1778-3801

\section{Éditeur :}

Centre d'Histoire et Théorie des Arts, Groupe d'Anthropologie Historique de l'Occident Médiéval, Laboratoire d'Anthropologie Sociale, UMR 8210 Anthropologie et Histoire des Mondes Antiques

\section{Référence électronique}

Georges Didi-Huberman, «Introduction », Images Re-vues [En ligne], Hors-série 2 | 2010, document 1, mis en ligne le 01 janvier 2010, consulté le 03 février 2021. URL : http://journals.openedition.org/ imagesrevues/276 ; DOI : https://doi.org/10.4000/imagesrevues.276

Ce document a été généré automatiquement le 3 février 2021.

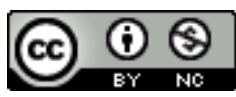

Images Re-vues est mise à disposition selon les termes de la Licence Creative Commons Attribution Pas d'Utilisation Commerciale 4.0 International. 


\title{
Introduction
}

\author{
Georges Didi-Huberman
}

1 Nous avons choisi, pour titre de ce colloque, L'Histoire de l'art depuis Walter Benjamin. Cela signifie sans doute que nous avons voulu nous interroger sur nos propres façons de pratiquer l'histoire de l'art depuis le temps où Benjamin, dans ses travaux sur l'art baroque ou le surréalisme, sur le théâtre épique ou sur la photographie, proposa certaines voies, cruciales, de recherche et de réflexion. Cela signifie surtout que nous nous

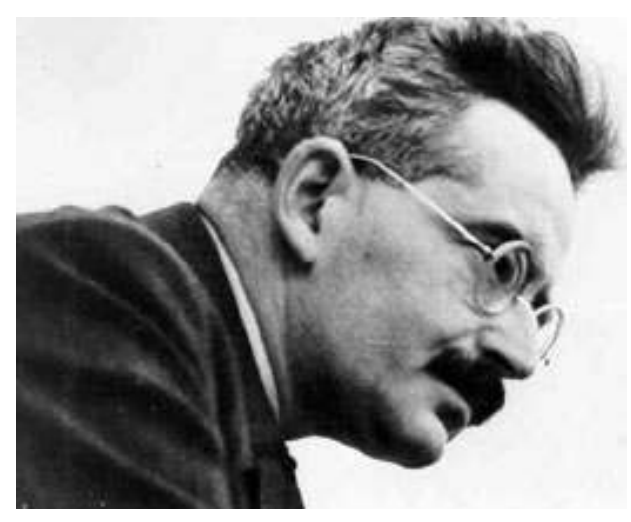
interrogeons sur ce que sont l'histoire, l'art, l'histoire de l'art, depuis la pensée de Walter Benjamin, je veux dire depuis le lieu même de cette pensée. Les historiens de la littérature, de la photographie et du cinéma sont depuis longtemps familiarisés avec les essais de Benjamin sur le conteur ou sur la reproductibilité technique des images. On ne peut sans doute pas en dire autant des historiens de l'art (ni, d'ailleurs, des historiens en général : en l'an 2000, le nom de Benjamin n'était toujours pas apparu dans les colonnes de la revue Annales depuis sa création en 1929).

2 Il faut dire que la pensée de Benjamin représente, pour toute discipline historique, quelque chose d'horripilant, si vous me permettez de jouer sur la fameuse manière benjaminienne de prendre les choses - les choses du temps - «à rebrousse-poil». Horripilant et, somme toute, difficile à comprendre : d'un côté il affirme violemment, dans une lettre à son ami Florens Christian Rang du 9 décembre 1923: "Je tiens désormais pour acquis qu'il n'y a pas d'histoire de l'art » (daß es Kunstgeschichte nicht gibt). D'un autre côté, il affirme modestement, dans un curriculum vitae rédigé en 1925 et repris en 1940, que le premier grand penseur à l'avoir influencé est un historien de l'art, Alois Riegl... À qui il faut ajouter Aby Warburg dont il rêva d'intégrer l'équipe en 
1928 (ses tentatives infructueuses dues au rejet de Panofsky ont été récemment analysées et exhaustivement documentées par Sigrid Weigel ${ }^{1}$ ).

Cette contradiction n'est qu'apparente. Car elle offre la signature d'une vitale exigence à l'égard de toute théorie et de toute histoire des arts. L'exigence de penser au-delà des oppositions canoniques formant le cadre d'intelligibilité de l'histoire de l'art comme discipline humaniste, par exemple l'opposition entre forme et matière, entre forme et contenu ou entre "grande » et "petite» forme. Penser au-delà : faire irradier, en quelque sorte, l'historicité des œuvres, des images, dans les deux sens qu'il nomme la Vorgeschichte et la Nachgeschichte, dans son livre sur le drame baroque allemand. Façon d'affirmer, après Warburg, que l'histoire de l'art est une histoire de survivances (et pas seulement de traditions)... si l'on n'oublie pas cette clause capitale, dialectique, que toute image, fût-elle mnémonique ou réminiscente, est douée d'une «actualité intégrale de tous côtés ouverte", comme Benjamin l'écrit en 1940 dans les Paralipomènes de ses thèses sur le concept d'histoire. Et si l'on n'oublie pas que l'«actualité des survivances " ouvre elle-même l'histoire de l'art à quelque chose de fondamental que Benjamin nomme une histoire de prophéties (politiques notamment).

4 Telle est bien la dialectique des images. Telle est l'« image dialectique » selon Benjamin. Elle suppose de multiplier les points de vue. Elle suppose qu'il n'y a pas d'histoire de l'art sans une véritable philosophie du temps (cf. la contribution de Giovanni Careri), qu'il n'y a pas d'histoire de l'art sans une philosophie de la culture (souci immanent aux propos d'André Gunthert, de Jean-Louis Déotte et de Muriel Pic), qu'il n'y a pas d'histoire de l'art sans une philosophie politique (comme Éric Michaud nous le montre), et qu'enfin il n'y a pas d'histoire de l'art, si lointain, si ancien soit celui-ci, sans une philosophie de la contemporanéité (Xavier Vert et Bernhard Rüdiger nous en font partager l'expérience).

\section{NOTES}

1. Sigrid Weigel, Walter Benjamin. Die Kreatur, das Heilige, die Bilder. Francfort-sur-le-Main, Fischer Taschenbuch Verlag, 2008, p. 228-264.

\section{AUTEUR}

\section{GEORGES DIDI-HUBERMAN}

Philosophe et historien de l'art, enseigne à l'EHESS (Paris). II a publié une trentaine d'ouvrages sur l'histoire et la théorie des images, dans un large champ d'étude qui va de la Renaissance 
jusqu'à l'art contemporain, et qui comprend notamment les problèmes d'iconographie scientifique au XIXème siècle et leurs usages par les courants artistiques du XXème siècle. 